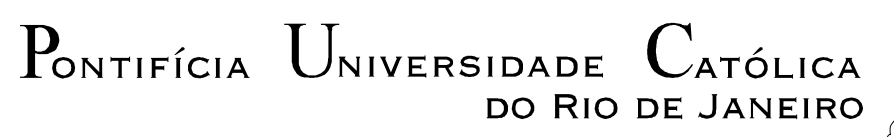

DO RIO DE JANEIRO

Maria Graciema Aché de Andrade

\title{
A POESIA ARCANGÉLICA DE GEORGES BATAILLE
}

\author{
Dissertação de Mestrado
}

Dissertação de Mestrado apresentada como requisito parcial para obtenção do grau de Mestre em Letras do Departamento de Letras da PUC-Rio como parte dos requisitos parciais para obtenção do título de Mestre em Letras.

Orientadora: Profa. Ana Paula Kiffer Co-orientador: Prof. Paulo Henriques Britto 

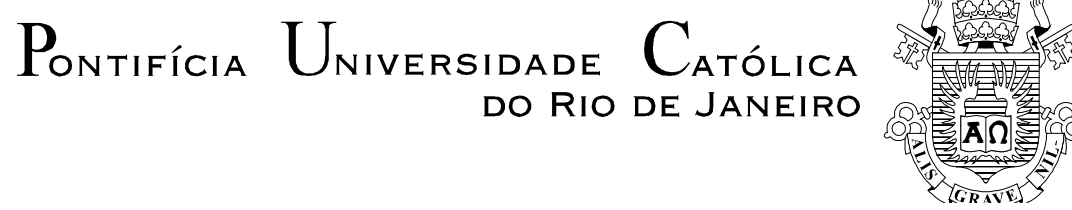

Maria Graciema Aché de Andrade

\title{
A POESIA ARCANGÉLICA DE GEORGES BATAILLE
}

Dissertação apresentada como requisito parcial para obtenção do grau de Mestre pelo programa de Pós-Graduação em Letras do Departamento de Letras do Centro de Teologia e Ciências Humanas da PUC-Rio. Aprovada pela Comissão Examinadora abaixo assinada.

\author{
Profa. Ana Paula Veiga Kiffer \\ Orientadora \\ Departamento de Letras - PUC-Rio \\ Prof. Paulo Fernando Henriques Britto \\ Co-Orientador \\ Departamento de Letras - PUC-Rio
}

Profa. Paula Glenadel Leal

UFF

Prof. Marcelo Jacques de Moraes

UFRJ

Prof. Paulo Fernando Carneiro de Andrade

Coordenador Setorial do Centro de Teologia

e Ciências Humanas - PUC-Rio

Rio de Janeiro,13 de abril de 2010 . 
Todos os direitos reservados. É proibida a reprodução total ou parcial do trabalho sem autorização da universidade, da autora e da orientadora.

\section{Maria Graciema Aché de Andrade}

Graduou-se em Ciências Sociais na PUC-Rio no ano de 2002. Ao longo do período de graduação aprofundou seu conhecimento e desenvolveu o olhar sobre a questão da antropologia visual em cursos sobre a prática do documentário com Eduardo Coutinho (direção de documentário, Videofundição) e João Moreira Salles (história do documentário - Videofundição). E cursou o Ateliê de Antropologia Visual da Universidade Estadual do Rio de Janeiro.

Ficha Catalográfica

Andrade, Maria Graciema Aché de

A poesia arcangélica de Georges Bataille / Maria Graciema Aché de Andrade ; orientadora: Ana Paula Kiffer ; co-orientador: Paulo Henriques Britto. 2010.

169 f. ; $30 \mathrm{~cm}$

Dissertação (Mestrado em Letras)Pontifícia Universidade Católica do Rio de Janeiro, Rio de Janeiro, 2010.

Inclui bibliografia

1. Letras - Teses. 2. Poesia. 3. Linguagem. 4. Morte. 5. Mal. 6. Nãosaber. 7. Desconhecido. 8. Impossível. 9. llimitado. 10. Erotismo. 11. Experiência. 12. Ser sensível. I. Kiffer, Ana Paula. II. Britto, Paulo Henriques. III. Pontifícia Universidade Católica do Rio de Janeiro. Departamento de Letras. IV. Título. 


\section{Agradecimentos}

Aos meus orientadores, Ana e Paulo, por me mostrarem, com tanta generosidade, de que são feitas a poesia e a literatura.

Ao Mathieu Dosse, ao Marcelo Jacques, à Clara e ao Robert Linhart, pela colaboração indispensável à tradução d'O Arcangélico.

Ao Daniel Guimarães, pela apresentação à poesia de Georges Bataille.

À minha mãe, Cristina, pelo suporte e afeto incondicionais.

Aos meus irmãos, avó, primos, tios e amigos, pelo incentivo, ânimo e paciência.

E ao Pedro, pelas noites e dias possíveis e impossíveis. 


\section{Resumo}

Andrade, Maria Graciema Aché de ; Kiffer, Ana Paula Veiga. A poesia arcangélica de Georges Bataille. Rio de Janeiro, 2010. 169p. Dissertação de Mestrado - Departamento de Letras, Pontifícia Universidade Católica do Rio de Janeiro.

A poesia arcangélica de Georges Bataille versa sobre o único livro do autor integralmente composto por poemas, L'Archangélique ( $\mathrm{O}$ Arcangélico), publicado pelo autor em Paris, em 1944. O presente estudo consiste numa tradução da obra para o português, de uma leitura dos poemas, do levantamento da teoria do autor sobre a poesia, e de uma problematização da experiência da tradução dentro dos termos do que seja a experiência poética tal como entendido por Bataille.

\section{Palavras-chave}

Poesia, linguagem, morte, mal, não-saber, desconhecido, impossível, ilimitado, erotismo, experiência, ser sensível. 


\section{Abstract}

Andrade, Maria Graciema Aché de; Kiffer, Ana Paula Veiga (Advisor).

Georges Bataille's archangelical poetry. Rio de Janeiro, 2010. 169p.

MSc. Dissertation - Departamento de Letras, Pontifícia Universidade

Católica do Rio de Janeiro.

Georges Bataille's archangelical poetry is a study dedicated to Bataille's only book entirely made up of poems, L'Archangélique (The Archangelic), published in Paris in 1944. The study consists of the book's translation, from French to Portuguese, followed by a reading of the poems, a review of Bataille's theory of poetry and also some issues on the translation experience that is thought to be proposed in terms of Bataille's poetic experience.

\section{Keywords}

Poetry, language, death, evil, unknown, impossible, ilimited, erotism, experience, being, sensible. 


\section{Sumário}

$\begin{array}{ll}\text { 1. Introdução } & 9\end{array}$

2. A questão poética em Bataille 25

2.1. A teoria em Bataille 25

2.1.1. O mal e a soberania 25

2.1.2. Entre o heterogêneo e a religião 42

2.1.3. O erotismo na poesia 51

2.1.4. O extremo da poesia 56

2.1.5. Ser poesia 68

2.2. Curto circuito crítico 75

2.3. Observações finais acerca da noção teórica 82

3. O Argélico 88

3.1. Versão para o português 88

3.2. A leitura 101

3.2.1. O Túmulo 105

3.2.2. A Aurora 115

3.2.3. O Vazio 119

3.3. Considerações finais acerca d` $O$ arcangélico 120

3.4. A experiência da tradução como experiência poética 125

3.4.1 Reflexos da teoria de Bataille: tradução, uma experiência interior? 125

3.4.2. Eu, tradutora por necessidade 134

3.4.3. As perdas, caso a caso 136

3.4.3.1. Adaptações 136

3.4.3.2. Duliedades 141

3.4.3.3. Concordância 143

$\begin{array}{ll}\text { 3.4.3.4. Registro } & 144\end{array}$

$\begin{array}{ll}\text { 3.5. Última observação } & 147\end{array}$

4. Referências Bibliográficas 150

5. Anexos 154

5.1. Comparação das escansões 154 
Imagino a liberdade de uma nuvem tomando o céu, se fazendo e se desfazendo com uma rapidez sem pressa, tirando da inconsistência e do dilaceramento o poder de invadir. G.BATAILLE (L'Impossible) 